\title{
Acolhimento dos acompanhantes de mulheres em processo de parto numa maternidade de alto risco
}

\author{
Reception of companions of women in labor in a high risk maternity ward
}

\section{Acogida de los acompañantes de mujeres en trabajo de parto en una maternidad de alto} riesgo

Recebido: $19 / 02 / 2020$

Aprovado: 21/07/2020

Publicado: 22/09/2020
Dayeny Fernandes Farago ${ }^{1}$

Tatiana Brusamarello2 Silvana Regina Rossi Kissula Souza ${ }^{3}$

O objetivo deste estudo é descrever o acolhimento do acompanhante de mulheres em processo de parto e nascimento numa maternidade de alto risco. Trata-se de uma pesquisa qualitativa descritiva realizada de junho a outubro de 2019, por meio de entrevista semiestruturada com 12 acompanhantes (dos quais nove homens) de puérperas internadas no centro obstétrico de um hospital universitário do Sul do Brasil. Para organização e análise dos dados utilizou-se o software WebQda e análise de conteúdo proposta por Bardin. Emergiram quatro categorias: Ambiência e confortabilidade na visão dos acompanhantes; Inclusão do acompanhante no processo de cuidar; Protagonismo do acompanhante no processo de parto e nascimento; e, Importância da participação do acompanhante no pré-natal. Mesmo diante do cenário crítico e de alta complexidade, que permeia uma maternidade de alto risco, a fala dos participantes desta pesquisa evidenciou que os mesmos se sentiram confortáveis e bem acolhidos. De modo que, o cuidado pôde ser compartilhado entre os mesmos e a equipe de saúde.

Descritores: Acolhimento; Humanização da Assistência; Parto Humanizado; Enfermagem.

The aim of this study is to describe the reception of companions of women in the process of childbirth and birth in a high-risk maternity. This is a descriptive qualitative research carried out between June and October of 2019, through a semi-structured interview with 12 companions (including nine men) of puerperal women admitted to the obstetric center of a university hospital in southern Brazil. For data organization and analysis, the WebQda software and content analysis proposed by Bardin were used. Four categories emerged: Ambience and comfort in the companions' view; Inclusion of the companion in the care process; Appreciation of the role of the companion in the delivery and birth process; and Importance of the companion's participation in prenatal care. Even with the critical and highly complex scenario, which permeates a high-risk maternity, the speech of participants in this research showed that they felt comfortable and welcomed. So, care could be shared between them and the health team.

Descriptors: User Embracement; Humanization of Assistance; Humanizing Delivery; Nursing.

El objetivo de este estudio es describir la acogida del acompañante de las mujeres en el proceso de parto y nacimiento en una maternidad de alto riesgo. Se trata de una encuesta cualitativa descriptiva realizada entre junio y octubre de 2019, mediante una entrevista semiestructurada con 12 acompañantes (nueve de ellos hombres) de mujeres puérperas ingresadas en el centro obstétrico de un hospital universitario del sur de Brasil. El software WebQda y el análisis de contenido propuesto por Bardin se utilizaron para organizar y analizar los datos. Surgieron cuatro categorías: Ambiente y comodidad en la visión de los acompañantes; Inclusión del acompañante en el proceso de atención; Protagonismo del acompañante en el proceso de parto y nacimiento; e, Importancia de la participación del acompañante en el prenatal. Incluso ante el crítico y altamente complejo escenario que impregna una maternidad de alto riesgo, el discurso de los participantes en esta investigación demostró que se sentían cómodos y recibidos. De esta manera, el cuidado pudo ser compartido entre ellos y el equipo de salud.

Descriptores: Acogimiento; Humanización de la Atención; Parto Humanizado; Enfermería.

1. Enfermeira. Especializanda na modalidade Residência Multiprofissional em Atenção Hospitalar (RMAH), com área de concentração em saúde da mulher, do Complexo Hospital de Clínicas (CHC) da Universidade Federal do Paraná (UFPR), Curitiba, PR, Brasil. ORCID: 0000-0002-5921-9571 E-mail: dayenyfarago@gmail.com

2. Enfermeira. Especialista em Qualidade e Segurança no Cuidado ao Paciente. Mestre e Doutora em Enfermagem. Coordenadora do eixo profissional da RMAH do CHC da UFRP, Curitiba, PR, Brasil. ORCID: 0000-0002-8060-8723 E-mail: brusamarello.tatiana@gmail.com

3. Enfermeira. Especialista em Enfermagem Obstétrica. Mestre em Engenharia de Produção. Doutora em Ciências. Professora e Vice Coordenadora do Programa de Pós Graduação em Enfermagem da UFPR, Curitiba, PR, Brasil. ORCID: 0000-0002-1679-4007 E-mail: skissula@gmail.com 


\section{INTRODUÇÃO}

$\mathbf{0}$ acolhimento é uma das diretrizes da Política Nacional de Humanização (PNH) divulgada pelo Ministério da Saúde (MS), que preconiza que este deve ser realizado por todos os profissionais de saúde e a qualquer tempo, e que este cuidado deve ser direcionado não somente aos pacientes, mas também aos seus acompanhantes ${ }^{1}$.

0 acolhimento nos serviços de saúde contribui para o desenvolvimento de relações humanizadas, promove a construção de vínculo entre a família, paciente e a equipe de saúde. Porém, muitas vezes, o acolhimento é mal compreendido pelos profissionais que atuam nos serviços de saúde restringindo este cuidado a uma das etapas do atendimento que ocorre na entrada dos serviços, por meio de recepções e triagens ${ }^{2}$.

A presença de acompanhantes sempre fez parte da história do processo de parto e nascimento, porém a institucionalização destes eventos a partir das práticas médicas obstétricas do século XX culminou no afastamento de familiares ou pessoa de convívio social das mulheres no momento do parto, e o que antes era um acontecimento domiciliar e familiar, tornou-se um processo médico, cercado de intervenções. Contudo nas últimas décadas estes modelos têm sido repensados por meio de recomendações das boas práticas na atenção ao parto e nascimento, e assim os familiares ou pessoas do convívio social das mulheres estão sendo reinseridos nestes cenários ${ }^{3}$.

Desde 1996 a Organização Mundial de Saúde recomenda as boas práticas de atenção ao parto e nascimento, e dentre essas estimula que as instituições respeitem a escolha da mulher sobre seus acompanhantes durante o processo de parto e nascimento. No Brasil, porém, esse direito passou a ser respeitado apenas mais tardiamente, no ano de 2005 quando estabelecida a Lei no 11.108, que determina que os serviços do Sistema Único de Saúde (SUS), da rede própria ou conveniada, ficam obrigados a permitir a presença, junto à parturiente, de um acompanhante indicado pela mesma durante todo o período de trabalho de parto, parto e pósparto imediato ${ }^{4,5}$.

A PNH ressalta que não basta que as instituições garantam o direito a acompanhante, mas que este seja promovido por meio de espaços para acolhê-los de forma que possam manter momentos de encontros, diálogos, relaxamento e entretenimento, independentemente do tipo de unidade, o que inclui pronto socorros, enfermarias, salas de espera dos centros cirúrgicos, centros obstétricos, dentre outras ${ }^{1}$.

A partir do momento que os acompanhantes adentram os serviços de saúde, podem se tornar parte do cuidado dos profissionais. Além disso, os estudos demonstram que o acolhimento e o conforto dos familiares no ambiente hospitalar se trata de objeto complexo e que requer abordagem multidisciplinar ${ }^{2,6}$.

Entende-se assim, que conhecer como é o acolhimento oferecido aos acompanhantes de mulheres em maternidades durante o processo de parto e nascimento poderá contribuir para confirmação da efetividade das ações já realizadas e/ou para desenvolvimento de melhorias, de forma a aperfeiçoar a assistência prestada aos acompanhantes e seus familiares. Diante do exposto, este estudo tem como objetivo descrever o acolhimento do acompanhante de mulheres em processo de parto e nascimento de uma maternidade de alto risco.

\section{MÉTODO}

Estudo de abordagem qualitativa, do tipo descritivo, realizado numa maternidade de alto risco de um hospital universitário do Sul do Brasil no período de junho a outubro de 2019.

O cenário da pesquisa é um complexo hospitalar de alta complexidade, assim conta com suporte para atender a maior parte das necessidades das "gestantes de risco". 0 perfil das gestantes atendidas nesta maternidade é de mulheres com doenças crônicas, doenças agudas exclusivas da gestação, com situações de vulnerabilidade social, gemelaridade, e outras. Sobre a estrutura da unidade de Centro Cirúrgico Obstétrico e Ginecológico (CCOG), este contém 
suítes privativas de pré-parto, parto e pós-parto, salas cirúrgicas, sala de reanimação neonatal, salas de tratamento clínico e recuperação anestésica ${ }^{7,8}$.

Participaram da pesquisa os acompanhantes de mulheres internadas no CCOG, convidados pela pesquisadora durante o puerpério de suas companheiras, após explicação da pesquisa e mediante assinatura do Termo de consentimento livre esclarecido. Os critérios de inclusão para o estudo foram: ser maior de 18 anos de idade e ter permanência mínima de 6 horas como acompanhante. Como critérios de exclusão: não compreender a língua portuguesa e não estar em condições emocionais para responder aos questionamentos da pesquisa.

A coleta de dados foi realizada por meio de entrevista semiestruturada, em salas privativas na maternidade, com a seguinte solicitação inicial: "Conte-me como você foi acolhido nesta maternidade durante o internamento de sua companheira." Para garantir o sigilo os participantes receberam uma identificação alfanumérica com a letra A (A1, A2, A3, sequencial conforme ordem das entrevistas).

Para a análise dos dados utilizou-se a Análise de Conteúdo proposta por Bardin, composta por três etapas: pré-análise; exploração do material, tratamento e interpretação dos resultados. Essa análise permite a identificação de categorias temáticas, que neste estudo foram elaboradas e organizadas com o auxílio do software webQDA, de apoio para pesquisa qualitativa, que tem como base para desenvolvimento a análise de conteúdo ${ }^{10,11}$.

A utilização do software webQDA é via internet, sem necessidade de instalação do programa no computador, e possibilita editar, visualizar, interligar e organizar os dados coletados. 0 software oferece três ferramentas principais: Fonte, espaço na qual são carregados os documentos do pesquisador (entrevistas transcritas em documentos de texto, vídeos ou imagens); Codificação, na qual se pode criar dimensões, indicadores ou categorias; e Questionamento, recurso que permite ao pesquisador questionar os dados com elaboração de matrizes ou contagem de palavras 9 .

Neste estudo as entrevistas foram gravadas em áudio e transcritas, posteriormente os arquivos de texto foram carregados no software e utilizou-se a ferramenta Fonte para caracterização dos participantes e a Codificação livre para definição de categorias. O software ainda possibilita identificar valores de "Referência" nas falas dos participantes, que representa o quanto do total da entrevista os mesmos se referiram a determinada temática ${ }^{9}$.

Este estudo foi aprovado pelo Comitê de Ética em Pesquisa, parecer no 3.320.550. Foram respeitados os aspectos éticos da Resolução no 466/12, sendo que todos os participantes assinaram o Termo de Consentimento Livre e Esclarecido.

\section{RESULTADOS}

Dos 12 participantes do estudo, nove se identificaram como gênero masculino e três femininos com faixa etária prevalente entre 25 a 29 anos. Em relação a cidade de origem, 11 são procedentes de Curitiba-PR e apenas um é do município de Araucária-PR, cidade metropolitana de Curitiba. Com relação à raça/cor autodeclarada, seis se identificaram como brancos, cinco como pardos e um como preto. A escolaridade com maior prevalência foi ensino médio completo, com sete participantes, seguida de dois com ensino fundamental incompleto, dois com ensino superior completo, e um com ensino médio incompleto (Tabela 1).

Em relação à ocupação, utilizou-se a Classificação Brasileira de Ocupações (CBO) do Ministério do Trabalho e Emprego, que organiza as ocupações em grandes grupos. 0 grande grupo 7 (Trabalhadores da produção de bens e serviços industriais), foi o que apresentou maior número de casos, com 4 acompanhantes. Ao abrir o leque de ocupações dos grandes grupos da CBO, é possível ver que a ocupações que aparecem entre os acompanhantes são, por exemplo: pintor, auxiliar de motorista, cozinheira, e outros. As ocupações que não são classificadas na CBO estão distribuídas neste estudo dentro da divisão "Outros", que incluem aposentados e desempregados ${ }^{12}$ (Tabela 1). 
Sobre o vínculo social com as pacientes internadas, cinco disseram que vivem em união estável, quatro são casados, duas mães e uma cunhada. Quando questionados em relação ao tempo de permanência como acompanhantes a maioria declarou estar há mais de 24 horas na maternidade (Tabela 1).

Tabela 1. Acompanhantes de mulheres em processo de parto e nascimento numa maternidade de alto risco, conforme classificação de fontes do software webQDA. Curitiba/PR, 2019.

\begin{tabular}{|c|c|}
\hline 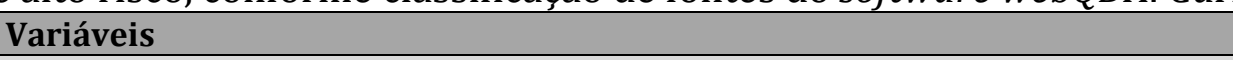 & Número \\
\hline \multicolumn{2}{|l|}{ Idade } \\
\hline $20-24$ anos & 2 \\
\hline $25-29$ anos & 4 \\
\hline $30-34$ anos & 2 \\
\hline $35-39$ anos & 2 \\
\hline $60-64$ anos & 1 \\
\hline $75-79$ anos & 1 \\
\hline \multicolumn{2}{|l|}{ Sexo } \\
\hline Homem & 9 \\
\hline Mulher & 3 \\
\hline \multicolumn{2}{|l|}{ Procedência } \\
\hline Curitiba - PR & 11 \\
\hline Araucária - PR & 1 \\
\hline \multicolumn{2}{|l|}{ Nível de instrução } \\
\hline Fundamental Incompleto & 2 \\
\hline Médio Incompleto & 1 \\
\hline Médio Completo & 7 \\
\hline Superior Completo & 2 \\
\hline \multicolumn{2}{|l|}{ Ocupação } \\
\hline Grande grupo 2 CBO - Profissionais das ciências e das artes & 1 \\
\hline Grande grupo 4 CBO - Trabalhadores de serviços administrativos & 1 \\
\hline \multicolumn{2}{|l|}{ Grande grupo 5 CBO - Trabalhadores dos serviços, vendedores do comércio em } \\
\hline lojas e mercados & 3 \\
\hline Grande grupo 7 CBO - Trabalhadores da produção de bens e serviços industriais & 4 \\
\hline Outros - Desempregados & 1 \\
\hline Outros - Aposentados & 2 \\
\hline \multicolumn{2}{|l|}{ Tipo de vínculo com a paciente } \\
\hline Vivem em união & 5 \\
\hline Cunhada & 1 \\
\hline Casado & 4 \\
\hline Mãe & 2 \\
\hline \multicolumn{2}{|l|}{ Tempo aproximado de permanência na maternidade } \\
\hline $6-12$ horas & 1 \\
\hline $13-18$ horas & 2 \\
\hline $19-24$ horas & 1 \\
\hline Maior que 24 horas & 8 \\
\hline \multicolumn{2}{|l|}{ Raça / Cor autodeclarada } \\
\hline Parda & 5 \\
\hline Branca & 6 \\
\hline Preta & 1 \\
\hline
\end{tabular}

Após análise das entrevistas emergiram quatro categorias: Ambiência e confortabilidade na visão dos acompanhantes; Inclusão do acompanhante no processo de cuidar; Protagonismo do acompanhante no processo de parto e nascimento; e, Importância da participação do acompanhante no pré-natal, representadas na Figura 1. 


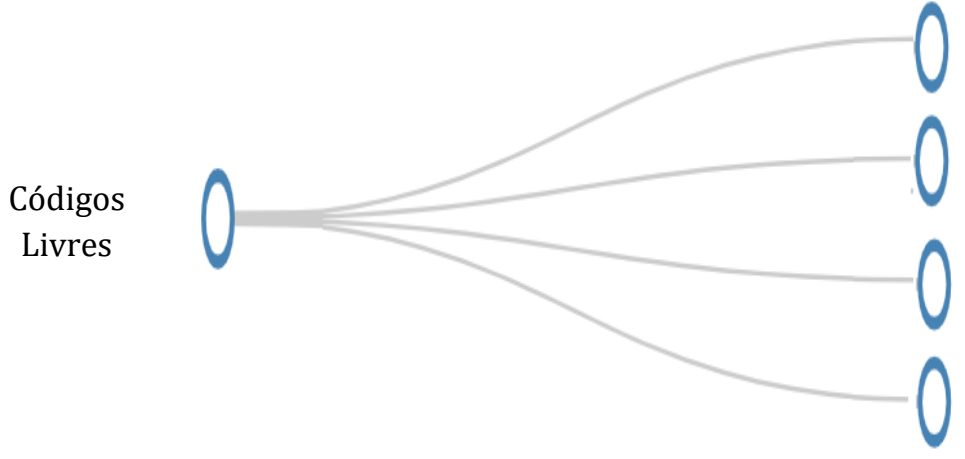

Ambiência e confortabilidade na visão do acompanhante

Inclusão do acompanhante no processo de cuidar

Valorização do acompanhante no processo de parto e nascimento

Importância da participação do acompanhante no pré-natal

Figura 1. Categorias temáticas que emergiram a partir do discurso dos participantes, conforme mapa de códigos livres gerados pelo software webQDA. Curitiba/PR, 2019.

\section{Ambiência e confortabilidade na visão do acompanhante}

Nesta categoria destacou-se o acolhimento oferecido por parte dos profissionais. Os participantes relataram como foram bem acolhidos pelos profissionais da instituição, uma vez que estes sempre se colocaram à disposição para sanar suas dúvidas e questionamentos. Referiram ainda, que a equipe foi afetuosa, respeitosa e ágil no atendimento de suas companheiras:

Todos os profissionais atenderam a gente bem, tanto ela enquanto paciente e eu como acompanhante, as meninas são bem atenciosas [...] vinham, falavam se estava perto do bebê nascer, se não estava. [...] A agilidade no atendimento e a calma, principalmente quando a pessoa vem ganhar um bebê precisa de um ambiente calmo, os profissionais da maternidade são muito calmos, muito tranquilos. (A3 - Referência - 32,72 \%).

O parto foi feito no mesmo quarto também, com as induções, as médicas vinham toda hora perguntar se nós estávamos bem, não só minha esposa, a mim também. [...] em nenhum momento fui maltratado, sempre tratado com educação, com carinho mesmo, dava para ver no rosto delas a vontade de trabalhar, e sem falar que o maior retorno para mim é cuidar da minha esposa, cuidaram muito bem dela, para mim está sendo ótimo. (A7 - Referência - 15,43\%).

Também foram valorizadas pelos participantes a estrutura física e a alimentação ofertada aos acompanhantes, permitido dormir e se alimentar com conforto dentro da instituição. Os aspectos relacionados à higiene, privacidade, organização do ambiente e segurança também foram colocados de forma positiva pelos entrevistados, chegando a ser entendido, pelo participante A5, como uma extensão da sua casa:

É muito bom, eu não esperava, que até então a nossa maternidade de referência [cita o nome da outra maternidade], eu nunca tinha vindo aqui neste hospital. Quando eu cheguei eu falei nossa é aqui, estava impressionado com os quartos. Às vezes a gente vai no particular e não é assim. A estrutura aqui é fantástica. (A2 - Referência - 16,51 \%). Segurança é o acolhimento da gente, eu achei bem legal aqui, o espaço tudo, ficou bem legal as reformas que foram feitas. Me senti bem, me senti normal, como se tivesse em casa, não foi assim uma coisa diferente, foi como se tivesse em casa. (A5 - Referência - 7,83 \%).

Muito bom, o hospital é muito organizado, é muito lindo [...], tudo esterilizado, ela acabou de sair [da suíte de parto] e a menina [equipe de higiene] já limpou. [...] almocei, estava muito boa a comida. Gostei muito daqui sabe, quando eu entrei aqui [suíte de parto] tinha cama [poltrona reclinável], dormi a noite inteira. Tinha televisão, assisti novela, tinha banheiro, muito bem, dormi à vontade. (A6 - Referência - 15,81 \%).

\section{Inclusão do acompanhante no processo de cuidar}

Essa categoria é representada por falas significativas relacionadas ao estímulo recebido pelos acompanhantes por parte dos profissionais de saúde, para que estes participassem dos cuidados com as parturientes. Em alguns relatos também foi evidenciado que o acompanhante estava confortável a ponto de sentir-se parte do processo e sozinho tomar a iniciativa de encorajar a parturiente a utilizar os métodos não farmacológicos de alívio da dor:

Foi muito bom, porque, eu acho que é o trabalho dos profissionais estar ajudando e mostrando as coisas, como que tem que ser feito, como faz. Ela [paciente] não queria andar, e aí me falaram 'pai pega ela, e puxa ela para andar, porque tem que dar dilatação e tudo', levar ela para caminhar porque ela só queria ficar deitada, e deitada não ajuda no parto. (A9 - Referência - 17,03\%). 
Eu fiquei acompanhando [...] ajudava, levava para o banho, acompanhei todas as dores dela, todo o processo ali eu estava junto, [...] eu chamei os enfermeiros, eles entraram no quarto e foi ali mesmo o parto. Eu fiquei do lado, olhando, perguntando, ajudando ela fazer força. (A10 - Referência - 13,19\%).

Eu fiquei junto em todos os momentos, foi tudo bem. Consegui acompanhar o parto, ficar junto com ela, ajudar com as bolinhas [bolas suíças], ficar ajudando ela, colocar no chuveiro, na água quente. (A12 - Referência - 17,28\%).

\section{Valorização do acompanhante no processo de parto e nascimento}

Foi possível identificar que alguns participantes se sentiram valorizados pela equipe de saúde, referiram ter sidos incluídos nas etapas do processo de parto e nascimento o que lhes promoveu uma sensação de pertencimento àquele momento. Relataram ainda, que estar participando do processo contribuiu positivamente para o sucesso do parto, uma vez que a parturiente se sentiu segura com a presença de alguém de sua confiança durante os momentos de dor:

Eu estava junto com a ela [parturiente], o médico falou é uma decisão sua, daí ele se corrigiu e falou não, é uma decisão de vocês [...] eu participei do processo todo. (A2 - Referência - 4,93 \%).

Eu fui muito bem atendido, sem palavras, cuidado, zelo, não só com ela, assim comigo que estou de acompanhante [...], eles [profissionais] deixam o que estão fazendo de lado e vem te orientar [...] isso para mim é um belo tratamento, na verdade me deixou importante, não me achando, mas me deixou importante. (A7 - Referência - 7,07\%).

Minha presença acho que ajudou bastante, porque o pai acaba acalmando, [...] ou alguém da família. Eu não ia querer sentir uma dor assim e não ter ninguém da família, no meio de um monte de gente estranha. [...] geralmente quando tem o parto, eles perguntam se a mãe está bem, mas eles conversam, perguntam se você está bem, você vai assistir o parto, entendeu, eles passam aquela impressão que você também está fazendo parte. (A10 - Referência - 20,93 \%).

\section{Importância da participação do acompanhante no pré-natal}

Nesta categoria foi evidenciada a importância do familiar ou pessoa de convívio social da mulher gestante participar das consultas de pré-natal, momento em que se tem a oportunidade conhecer a legislação e seus direitos. De acordo com os relatos dos participantes, participar do pré-natal possibilitou conhecer as etapas do processo de parto e nascimento, saber dos seus direitos enquanto acompanhantes e estar mais confiantes durante sua permanência no centro obstétrico:

A gente fez o acompanhamento e desde a enfermeira de lá [durante o pré-natal na atenção básica], até as médicas, sempre tivemos acesso a informações [sobre o direito ao acompanhante] [...] e na entrada também tinha uma placa enorme assim na entrada [durante o pré-natal nesta maternidade]. (A2 - Referência - 9,69 \%).

Tem os informativos aqui na parede [sobre o direito à acompanhante] desde o começo que minha esposa começou a fazer o pré-natal aqui [durante o pré-natal nesta maternidade] [...] fizemos uma visita aqui também e a enfermeira foi bem clara que acompanhante não é qualquer um, que marido é sim acompanhante. (A7 - Referência - 7,79\%). Eu vi que tinha escrito ali na porta, quando você entra no pronto atendimento [durante o pré-natal nesta maternidade] tem que pai não é visita. (A10 - Referência - 10,53 \%).

\section{DISCUSSÃO}

Para o Ministério da Saúde (MS), a Ambiência nos serviços de saúde abrange o espaço físico, social, profissional e relações interpessoais, e estes devem estar em harmonia para estabelecer uma proposta de ações de saúde voltadas para a atenção acolhedora, resolutiva e humanizada. A ambiência é um dispositivo que contribui positivamente nas relações de trabalho, e por consequência nas relações interpessoais, e isso inclui a relação profissionais/profissionais e profissionais/usuários, pois é uma ferramenta que visa promover espaços saudáveis, acolhedores, confortáveis, com privacidade e de encontro entre as pessoas ${ }^{1}$.

Na categoria Ambiência e confortabilidade na visão do acompanhante, a ambiência foi evidenciada nas falas dos participantes quando estes se referiram ao bom acolhimento recebido por parte dos profissionais, quando foram tratados com palavras de afeto e gentileza. $\mathrm{Na}$ entrevista de A3, por exemplo, o software apontou um valor de "Referência de 32,72\%", isto demonstra o quanto este tema foi significativo para este participante, pois mais de $30 \%$ de toda sua entrevista foi direcionada ao quão bem foram atendidos pelos profissionais de saúde da instituição.

Já a questão do conforto, nesta primeira categoria, teve relevância significativa quando os participantes falaram sobre a estrutura física e alimentação oferecida pela instituição para os 
acompanhantes. Os apontamentos demonstraram que a instituição oferece meios de promover conforto e acolhimento aos seus usuários.

Esse fenômeno pode estar relacionado ao fato de que no ano de 2019 o CCOG da instituição foi reformado. 0 projeto foi planejado para aumentar o conforto de pacientes, acompanhantes e profissionais da unidade. Dentre as melhorias realizadas destaca-se salas com equipamentos de parto humanizado, como uma com banheira e outra completamente adequada para deficientes físicas, salas cirúrgicas amplas, ambiente climatizado e com cores claras, além de uma nova copa e sala de descanso para a equipe multiprofissional ${ }^{8}$.

A palavra conforto é definida como estado de bem-estar, pela qual, a experiência subjetiva excede à dimensão física, e inclui necessidades básicas no aspecto físico, psicológico, social, espiritual e ambiental; logo, o desconforto surge da não-satisfação de suprir essas necessidades ${ }^{13}$. A hospitalização de um familiar pode gerar diversas situações de desconforto para os acompanhantes, pois estes precisarão se adaptar às normas e rotinas da instituição, e para muitas pessoas o hospital é um cenário hostil, onde vivenciam situações de angústia e medos, o que altera totalmente sua rotina, costumes e hábitos diários ${ }^{13}$.

A confortabilidade segundo o MS é importante estratégia de humanização nos serviços de saúde, sendo importante oferecer ambiências confortáveis e acolhedoras, de modo a propiciar privacidade e individualidade dos usuários e trabalhadores de um determinado serviço de saúde. Destaca-se ainda, que o conforto ambiental, por meio da arquitetura, é uma das principais ferramentas para humanização hospitalar, em que se deve valorizar espaços de convivência dos usuários, através da cor, luz, texturas, sons, e até odores ${ }^{1,14}$.

Todos esses componentes abordados na categoria Ambiência e confortabilidade na visão do acompanhante atuam como qualificadores, promovendo acolhimento, que por consequência contribui para o processo de produção de saúde e de espaços saudáveis, tanto para usuários quanto para profissionais das instituições de saúde ${ }^{15}$.

Sobre a Inclusão do acompanhante no processo de cuidar, os resultados demonstraram que os acompanhantes nesta maternidade foram incluídos no processo de parto e nascimento de suas companheiras. Para a mulher a presença do acompanhante propícia, do ponto de vista fisiológico, estimulação da produção hormonal, diminuindo o seu estado de alerta e a ansiedade frente ao desconhecido, proporcionando mais serenidade e confiança, influenciando em desfechos mais favoráveis nos tratamentos recebidos ${ }^{16}$.

Em muitas falas surgiram palavras como "bola", "cavalinho", "banho", "caminhar", "chuveiro", "água quente", que demonstram que a instituição estudada adota as medidas não farmacológicas de alívio da dor no trabalho de parto, e que além de realizar tais práticas, inclui os acompanhantes nesses cuidados, promovendo então a humanização no atendimento à mulher no processo de parto e nascimento. 0 que vai ao encontro dos resultados de um estudo 15 realizado na região sul do país que evidenciou que a presença do acompanhante é estatisticamente associada à maior oferta de métodos não farmacológicos para alívio da dor no trabalho de parto ${ }^{17}$.

Destarte, as Diretrizes Nacionais de Assistência ao Parto Normal do MS recomendam que a equipe de saúde auxilie e oriente o acompanhante a se integrar no momento do processo de parto e nascimento, incentivando-o a dar apoio físico e emocional à parturiente ${ }^{16}$.

Para além do ponto de vista fisiológico, a presença do acompanhante favorece o fortalecimento do vínculo familiar, fato que fica evidenciado na categoria Valorização do Acompanhante no processo de parto e nascimento, falas em que os participantes reconhecem a importância da sua presença física para suas companheiras. Esses achados valorizam as recomendações estabelecidas na proposta HumanizaSUS sobre visita aberta e direito a acompanhante 18,19 .

Muitas instituições hospitalares, no decorrer da história, foram construídas com base em relações hierarquizadas e normatizadas, com modelos de assistência tecnicistas e excludentes. Assim diante da hospitalização de um familiar, o acompanhante se vê em um cenário 
desconhecido, onde precisa se adaptar aos protocolos, horários e rotinas institucionais, passíveis de serem manipulados por pessoas que podem omitir informações sobre o que deve, pode ou não fazer ${ }^{20}$.

As políticas de humanização e direitos estabelecidos para os acompanhantes e pessoas hospitalizadas fomentam mudanças nestes cenários:

A presença do acompanhante, do visitante, de familiar ou de representante da rede social do paciente no ambiente hospitalar é, indiscutivelmente, uma marca fundamental que pode mudar as relações de poder nas instituições de saúde, aumentando o grau de protagonismo dos usuários ${ }^{18}$.

Para o acompanhante um bom acolhimento por parte dos profissionais de saúde os faz perceber o espaço hospitalar como um lugar seguro, e para os profissionais também proporciona um ambiente de trabalho mais confortável e harmonioso, pois o acompanhante pode ser um grande aliado do cuidado no encorajamento à mulher no momento do parto ${ }^{16,18}$.

Na categoria Importância da participação do acompanhante no pré-natal, ficou claro que é neste momento que os acompanhantes passam a conhecer o direito da mulher em ter sua presença, garantido pela Lei 11.108, de 7 de abril de 2005, que dispõe sobre o direito de todas as mulheres atendidas nos serviços do SUS de serem acompanhadas por pessoa de sua escolha durante o trabalho de parto, parto e pós parto.

Os resultados dessa pesquisa divergem dos achados de outra pesquisa que demonstrou que as mulheres tiveram dificuldades em ter a presença de seus acompanhantes durante o parto e nascimento, devido a profissionais que ou desconheciam os direitos da parturiente ou simplesmente ignoravam a legislação ${ }^{21}$.

\section{CONCLUSÃO}

Os resultados alcançados neste estudo evidenciam que o processo de cuidado das mulheres hospitalizadas durante o parto e nascimento pode ser partilhado entre equipe de saúde e seus acompanhantes, para isso é importante que estes sejam bem acolhidos e orientados, e assim sintam-se confortáveis e incluídos no processo de cuidar de suas companheiras.

Identificou-se também que a presença do acompanhante fortalece o vínculo familiar entre os indivíduos, fato importante já que a família está prestes a receber um novo membro, o bebê, que levanta a necessidade de readequação da estrutura familiar e reorganização da rotina.

O local de condução de algumas entrevistas para a coleta de dados pode ter impactado na atenção e concentração dos participantes, pois foram realizadas no CCOG. Sendo este aspecto, portanto, uma limitação a ser considerada no presente estudo.

Por sua vez, diante do cenário crítico e de atendimento de alta complexidade, que permeia uma maternidade de alto risco, a instituição estudada e os profissionais que nela atuam, fazem mais do que cumprir a obrigatoriedade de permitir a entrada de acompanhantes de mulheres internadas para o processo de parto e nascimento, eles buscam respeitar as Políticas públicas das boas práticas de atenção ao parto nascimento e a PNH.

\section{REFERÊNCIAS}

1. Oliveira OVM. Política Nacional de Humanização: o que é como implementar (uma síntese das diretrizes e dispositivos da PNH em perguntas e respostas) [Internet]. Brasília, DF: Ministério da Saúde, Secretaria de Atenção à Saúde; 2010 [citado em 10 dez 2019]. Disponível em: http://www.redehumanizasus.net/sites/default/files/diretrizes_e_dispositivos_da_pnh1.pdf 2. Gibaut MAM, Hori LMR, Freitas KS, Mussi FC. Conforto de familiares de pessoas em Unidade de Terapia Intensiva frente ao acolhimento. Rev Esc Enferm USP. [Internet]. 2013 [citado em 01 out 2019]; 47(5):1117-24. DOI: https://doi.org/10.1590/S0080-623420130000500015 
Disponível em: https://www.scielo.br/pdf/reeusp/v47n5/pt_0080-6234-reeusp-47-051114.pdf

3. Santos MT, Ferreira WFS, Oliveira EM. Análise histórico contemporâneo de profissionais e parturientes com acompanhantes em obstetrícia. Discipl Scientia [Internet]. 2019 [citado em 16 fev 2020]; 20(1):53-60. Disponível https://periodicos.ufn.edu.br/index.php/disciplinarumS/article/view/2631/2379

4. World Health Organization. WHO recomendations : intrapartum care for a positive childbirth experience [Internet]. Geneva, 2018 [citado em 01 dez 2019]. Disponível em: https://apps.who.int/iris/bitstream/handle/10665/260178/9789241550215-

eng.pdf;jsessionid=E40DDF9998BA2D82B61D14CDC14A9E5C?sequence $=1$

5. Presidência da República (Brasil). Lei n. 11.108, de 7 de abril de 2005. Altera a Lei no 8.080, de 19 de setembro de 1990, para garantir às parturientes o direito à presença de acompanhante durante o trabalho de parto, parto e pós-parto imediato, no âmbito do Sistema Único de Saúde - SUS. Diário Oficial da União, [Internet]. 05 abr 2005 [citado em 01 ago 2018]. Disponível em: http://www.planalto.gov.br/ccivil_03/_Ato2004-2006/2005/Lei/L11108.htm

6. Gomes DC, Batista CML, Costa CS, Dantas MPS, Rangel JB, Lucena RS, et al. Acolhimento e humanização: potencializando a importância do acompanhante no processo de saúde do usuário [Internet]. In: 12 Congresso Internacional da Rede Unida; Encontros Regionais 20014/2015: Nordeste 1; 2015; Natal. Porto Alegre: Secretaria Executiva; 2015 [citado em 16 fev 2020]. Disponível

em:

http://conferencia2016.redeunida.org.br/ocs/index.php/regionais/nordeste1/paper/view/3451

7. Ministério da Saúde (Br). Secretaria de Atenção à Saúde, Departamento de Ações Programáticas Estratégicas. Gestação de alto risco: manual técnico [Internet]. 5ed. Brasília, DF: Editora MS; 2010 [citado em $10 \mathrm{dez}$ 2019]. 301p. (Serie A. Normas e manuais técnicos). Disponível em: http://bvsms.saude.gov.br/bvs/publicacoes/gestacao_alto_risco.pdf

8. Empresa Brasileira de Serviços Hospitalares, Complexo Hospital de Clínicas da Universidade Federal do Paraná. Assistência: reforma no Centro Obstétrico do CHC trará mais conforto e acessibilidade para as mães. Curitiba: Hospital de Clínicias; 09 abr 2019 [citado em 10 dez 2019]. Disponível em: http://www2.ebserh.gov.br/pt/web/chc-ufpr/detalhes-das-noticias//asset_publisher/7d2qZuJcLDFo/content/id/4003504/2019-04-reforma-no-centroobstetrico-do-chc-trara-mais-conforto-e-acessibilidade-para-as-maes

9. Bardin L. Análise de conteúdo. São Paulo: Edições 70; 2016.

10. Souza FN, Costa AP, Moreira A, Souza DN, Freitas F. WebQDA - manual de utilização rápida [Internet]. Aveiro, Portugal: UA Editora; 2016. [citado out 2019]. Disponível em: https://app.webqda.net/Fontes/Manual_de_Utilizacao_webQDA.pdf

11. Chaves MMN, Mafra MRP, Larocca LM. O Software webQDA no apoio à construção de conhecimento: um relato de experiência na pesquisa qualitativa. Fronteiras: J Soc Technol Environ Science [Internet]. 2015 [citado em dez 2019]; 4(3):81-6. Disponível em: https://doi.org/10.21664/2238-8869.2015v4i3.p81-86

12. Ministério do Trabalho e Emprego (Brasil). Classificação Brasileira de Ocupações : CBO [Internet]. 3ed. Brasília, DF: MTE, SPPE; 2010. 828p. [citado em 17 fev 2020]. Disponível em: http://www.cofen.gov.br/wp-content/uploads/2015/12/CLASSIFICA\%C3\%87\%C3\%830BRASILEIRA-DE-OCUPA\%C3\%87\%C3\%95ES-MEC.pdf

13. Gonçalves MCS, Brandão MAG, Duran ECM. Validação das características definidoras do diagnóstico de enfermagem conforto prejudicado em oncologia. Acta Paul Enferm. [Internet]. 2016 [citado em 15 fev 2020]; 29(1):115-24. Disponível em: https://doi.org/10.1590/19820194201600016

14. Souza NC. A história e o processo de humanização dos edifícios hospitalares [Internet]. [monografia]. Maringá, PR: UniCesumar; 2017 [citado em 01 fev 2020]. Disponível em: 
http://rdu.unicesumar.edu.br/xmlui/bitstream/handle/123456789/420/NATALYA\%20CHI LIGA\%20DE\%20SOUZA.pdf?sequence=1\&isAllowed=y

15. Ministério da Saúde (Br). Secretaria e Atenção à Saúde. Politica Nacional de Humanização: folheto [Internet]. Brasília, DF: Ministério da Saúde; 2013 [citado em 01 set 2018]. Disponível em:

http://bvsms.saude.gov.br/bvs/publicacoes/politica_nacional_humanizacao_pnh_folheto.pdf 16. Ministério da Saúde (Br). Diretrizes nacionais de assistência ao parto normal: versão resumida [Internet]. Brasília, DF: Editora do Ministério da Saúde; 2017 [citado em 01 dez 2019]. Disponível em: http://bvsms.saude.gov.br/bvs/publicacoes/diretrizes_nacionais_assistencia_parto_normal.p df

17. Monguilhott JJC, Brüggemann OM, Freitas PF, Orsi E. Nascer no Brasil: a presença do acompanhante favorece a aplicação das boas práticas na atenção ao parto na região Sul. Rev Saúde Pública [Internet]. 2018 [citado em 01 dez 2019]:52:1-11. Disponível em: https://doi.org/10.11606/S1518-8787.2018052006258

18. Ministério da Saúde (Br). Secretaria de Atenção à Saúde, Núcleo Técnico da Política Nacional de Humanização. HumanizaSUS: visita aberta e direito a acompanhante [Internet]. 2ed. Brasília, DF: Editora MS; 2007 [citado 01 nov 2018]. 31p. (Série B. Textos básicos de saúde). Disponível em: http://bvsms.saude.gov.br/bvs/publicacoes/visita_acompanhante_2ed.pdf

19. Souza SRRK, Gualda DMR. A experiência da mulher e de seu acompanhante no parto em uma maternidade pública. Texto \& Contexto Enferm. [Internet]. 2016 [citado em dez 2019]; 25(1):e4080014. Disponível em: https://doi.org/10.1590/0104-0707201600004080014

20. Squassante ND, Alvim NAT. Relação equipe de enfermagem e acompanhantes de clientes hospitalizados: implicações para o cuidado. Rev Bras Enferm. [Internet]. 2009 [citado em 01 dez 2019]; 62(1):11-7. Disponível em: https://doi.org/10.1590/S0034-71672009000100002 21. Silveira IP. Teoria do conforto para promoção da saúde no cuidado de enfermagem à parturiente [Internet]. [tese]. Fortaleza: Universidade Federal do Ceará; 2010 [citado em dez 2019]. Disponível

em: http://www.repositorio.ufc.br/bitstream/riufc/2100/1/2010_tese_ipsilveira.pdf

\section{CONTRIBUIÇÕES}

Dayeny Fernandes Farago contribuiu na concepção, coleta, análise, interpretação dos dados e redação. Silvana Regina Rossi Kissula Souza participou na concepção e revisão. Tatiana Brusamarello atuou na concepção, análise e interpretação dos dados e revisão.

\section{Como citar este artigo (Vancouver)}

Farago DF, Brusamarello T, Souza SRRK. Acolhimento dos acompanhantes de mulheres em processo de parto numa maternidade de alto risco. REFACS [Internet]. 2020 [citado em inserir dia, mês e ano de acesso]; 8(4):827-836. Disponível em: inserir link de acesso. DOI: inserir link do DOI.

\section{Como citar este artigo (ABNT)}

FARAGO, D. F.; BRUSAMARELLO, T.; SOUZA, S. R. R. K. Acolhimento dos acompanhantes de mulheres em processo de parto numa maternidade de alto risco. REFACS, Uberaba, MG, v. 8, n. 4, p. 827-836, 2020. Disponível em: inserir link de acesso. Acesso em: inserir dia, mês e ano de acesso. DOI: inserir link do DOI.

\section{Como citar este artigo (APA)}

Farago, D.F., Brusamarello, T., \& Souza S.R.R.K. (2020). Acolhimento dos acompanhantes de mulheres em processo de parto numa maternidade de alto risco. REFACS, 8(4), 827-836. Recuperado em inserir dia, mês e ano de acesso de inserir link de acesso. DOI: inserir link do DOI. 